\title{
Effects of Mechanochemical Pretreatment on the Extraction of Functional Materials from Houttuynia cordata
}

\author{
Keum Joo Park ${ }^{1 *}$, Won Seob Song ${ }^{2}$, Mohammad Nazrul Islam ${ }^{1}$, Jong Ill Lee ${ }^{3}$ and Yang Soo Kim ${ }^{4}$ \\ ${ }^{1}$ Department of Industrial Machinery Engineering, ${ }^{2}$ Department of Horticulture, ${ }^{3}$ Department of \\ Oriental Medicine Resources, Sunchon National University, Suncheon 540-742, Korea, \\ ${ }^{4}$ Suncheon Center, Korea Basic Science Institute, Suncheon 540-742, Korea
}

\begin{abstract}
Houttuynia cordata is used as a raw material of oriental medicine to acquire antioxidant and anti cancer effect and to cure a heart disease. Mechanochemical technology not only reduces the size of the object but also changes the chemical properties of the object. Extraction of functional materials from the Houttuynia cordata after grinding as a pretreatment using the mechanochemical technology was conducted in this study to investigate the effect of grinding on the yields and antioxidant activities of the extract. Houttuynia cordata was ground by the planetary ball mill and the morphology was analyzed by SEM. Yields of functional materials were increased from $6.2 \mathrm{~g}$ in the sample without grinding to 7.0, 7.8, 8.8 $\mathrm{g}$ after grinding of 30 minutes, 1 hour and 2 hours, respectively. Nitrite scavenging abilities were increased from $57-77 \%$ to $69-86 \%$ as a result of mechanochemical pretreatment. Also, DPPH scavenging abilities for the methanol extraction were increased from $10.01-40.29 \%$ to $11.01-49.29 \%$ as a result of mechanochemical grinding.
\end{abstract}

Key words - Mechanochemical grinding, Houttuynia cordata, Nitrite scavenging ability, Electron donating ability (EDA)

\section{Introduction}

Mechanochemical grinding is a technology leading physical and chemical change of material by operating mechanical stress and impact on the materials in the closed field. Mechanochemical operation not only gives the increase of surface of the materials but also induces the particle activation for the next reaction. This technology is widely used in the modification and synthesis of functional materials, treatment of wastes due to its simple process, energy savings and environmental safety.

Mechanochemical extraction technique was used for efficient and selective extraction of magnolol from Magnolia officinalis using a high intensive activator, AGO-2. Compared with superfine grinding extraction and heat-reflux extraction, mechanochemical extraction method reduced both extraction time and temperature, and also achieved a higher magnolol yield and content in the crude extracts (Xie et al., 2011). Mechanochemical-assisted extraction technology was applied for the extraction of rutin from Hibiscus mutabilis (Xie et al., 2011) and for the extraction of flavonoids and terpene trilactones from Ginkgo leaves

${ }^{*}$ Corresponding author. E-mail : pkj@sunchon.ac.kr
(Zhu et al., 2011). Also, mechanochemical technology was applied to make the quartz particle to be a surface-active material for the efficient extraction of desired materials (IImura et al., 2007; Palaniandy and Azizli, 2009; Zubrik et al., 2007).

Houttuynia cordata is used as the useful materials in oriental medicine. Houttuynia cordata is an attractive natural resource for herbal medicine such as antioxidant, anti-cancer effect, heart diseases and some other human diseases. Houttuynia cordata is also used in folk medicine for diuresis and detoxification, and in herbal medicine for its antiviral, antibacterial and antileukemic activities. Recently it has been suggested that it might have anti-obesity properties. Houttuynia cordata was used by Chinese scientists to tackle SARS (severe acute respiratory syndrome) as it was conventionally used to treat pneumonia.

However, the extraction of functional material is carried out using organic solvents such as methanol and ethanol leading to time consumption and environmental pollution during the process.

Thus, efficient extraction method of functional materials from some oriental medicine plants should be developed to 
simplify the process, to reduce energy consumption and to protect the ecological contamination. In this study, mechanochemical grinding was applied as the pretreatment process before methanol extraction for efficient and economic extraction.

\section{Materials and Methods}

\section{Plant material}

Houttuynia cordata grows in the shady forest in Korea (Ulleung-do, Anmyeon-do, Keoje-do), Japan, China, Himalayas Mountains, and Java Island. The stalk is upright and $20-50 \mathrm{~cm}$ in length with several lines in the stalk and without smell. Flowers open from May and June.

Houttuynia cordata was purchased from the medicinal stuff market of Geumsan, Chungbuk, in Korea and kept under room temperature.

\section{Mechanochemical operation}

Before mechanochemical grinding, preliminary grinding was carried out using domestic pulverizer to make an original stalk to small pieces of 1-2 mm. Fine grinding experimental work of Houttuynia cordata was carried out in a planetary mill with different grinding period. Totally about $15 \mathrm{~g}$ of pretreated materials were grounded by a planetary ball mill (Pulverisette-5, Fritsch, Germany), which has two mill pots $\left(100 \mathrm{~cm}^{3}\right.$ inner volume each) made of $\mathrm{ZrO}_{2}$. Seven $\mathrm{ZrO}_{2}$ balls of $15 \mathrm{~mm}$ in diameter were inputted in each pot for the optimal grinding. The grinding speed of planetary mill was $350 \mathrm{rpm}$ and the grinding periods were $30 \mathrm{~min}, 1$ hour and 2 hours. The ground products were characterized by scanning electron microscopy (SEM) and extraction of functional materials analysis.

\section{Extraction}

After mechanochemical grinding, powder was dissolved into methanol and ethanol for 5 weeks and taken with 3 replications and filtered using Whatman No.2 filter. After evaporation of the filtrate under reduced pressure using evaporation apparatus (Eyrla, Rotary evaporator), the powder was attained and subsequently analyzed for the extraction efficiency.

\section{Nitrite scavenging ability}

According to the standard method (Boo et al., 2011), after $1 \mathrm{~mL}$ of sample was inserted into the reagent $1 \mathrm{mM}$ of $\mathrm{NaNO}_{2}$, and using the $0.1 \mathrm{~N} \mathrm{HCl}$ and $0.2 \mathrm{M}$ buffering citric acid, $\mathrm{pH}$ was controlled to have 1.2, 3.0 and 6.0 each making the total volume of $10 \mathrm{~mL}$. After incubating above solution in a water bath at $37^{\circ} \mathrm{C}$ for $1 \mathrm{hr}$, took $1 \mathrm{~mL}$ of solution and added $5 \mathrm{~mL}$ of $2 \%$ acetic acid and $0.4 \mathrm{~mL}$ of Griess reagent (a 1:1 ratio of $1 \%$ sulfanilic acid in 30\% acetic acid and 1\% naphthylamine in $30 \%$ acetic acid). Afterward, the mixture was incubated for 15 minutes in room temperature. The residual nitrite capacity was determined by spectrophotometric analysis at $520 \mathrm{~nm}$. Control vial was made using the $1 \mathrm{~mL}$ of distilled water instead of sample. Nitrite scavenging ability was acquired by comparing the vial with extraction and the one without as follows:

Nitrite scavenging ability $(\%)=(1-$ absorbance of the solution with extraction/absorbance of the solution without extraction) x 100

\section{Electron donating ability (EDA)}

Antioxidant ability for the functional materials are determined by the measurement of free radical scavenging using DPPH (2,2-diphenyl-1-pycrylhydrazyl) radical, inhibition effect of MDA-BSA conjugation reaction, inhibition effect of tyrosinase, hydroxyl radical scavenging and etc. Among them, DPPH radical is commonly used for evaluating antioxidant effect in a relatively short time. The inhibition of DPPH radicals is determined by the decrease in their absorbance due to the antioxidant (Jun et al., 2009). Electron donating ability was determined by the method of DPPH (Yang et al., 2011). After dissolving $12 \mathrm{mg}$ of DPPH reagent into ethanol, added 50\% of ethanol to have absorbance 1 of DPPH solution at $517 \mathrm{~nm}$. Afterwords, $0.5 \mathrm{~mL}$ of extract was mixed with $5 \mathrm{~mL}$ of DPPH solution and measured absorbance. EDA was calculated by the following equation using the absorbance data with three replications.

$\operatorname{EDA}(\%)=\left(\mathrm{A}_{0}-\mathrm{A}\right) / \mathrm{A}_{0} * 100$

Where $\mathrm{A}_{0}$ : Absorbance of DPPH solution without sample A : Absorbance of DPPH solution mixed with extract 


\section{Results and Discussion}

Ground samples of Houttuynia cordata by planetary ball mill is shown in Fig. 1. Original sample indicates the ground one by domestic pulverizer to make an original stalk to small pieces before grinding by planetary ball mill. With the naked eye, significant difference could be found between the sample without and the samples with mechanochemical grinding. However, there was no distinguishable difference among samples due to the grinding time ( $30 \mathrm{mins}, 1 \mathrm{hr}, 2 \mathrm{hrs}$ ).

SEM photos were acquired for the ground materials of Houttuynia cordata with magnification of 500 and 2,000 times. The materials became much smaller with higher surface area after $1 \mathrm{hr}$ of grinding. There was not so much difference in particle size and morphology after $1 \mathrm{hr}$ of grinding.

\section{Extraction of functional materials}

The extraction amount of functional materials from Houttuynia cordata was increased from $6.2 \mathrm{~g}$ to $7.0,7.8$, and $8.8 \mathrm{~g}$ for the grinding time of $30 \mathrm{~min}, 1$ hour, and 2 hours, respectively.

\section{Nitrite scavenging ability}

To investigate the effect of mechanochemical pretreatment on the nitrite scavenging ability, the sample pulverized for 2 hrs by planetary ball mill was compared with the sample without grinding (control). The nitrite scavenging ability was determined by spectrophotometric analysis at $520 \mathrm{~nm}$.

As $\mathrm{pH}$ increased from 1.2 to 6.0 , nitrite scavenging ability decreased so much showing almost zero at $\mathrm{pH}$ 6.0. This result is consistent with the previous results indicating best nitrite scavenging ability in $\mathrm{pH}$ of 1.2 for the extract from onion peel, redbeet, yellow gardenia, mature foxglove and etc. (Boo et al., 2011). For the extract concentration, as the concentration varied from $50 \mu \mathrm{g} / \mathrm{mL}$ to $600 \mu \mathrm{g} / \mathrm{mL}$, nitrite scavenging ability increased. Comparing the solvent, nitrite scavenging

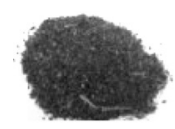

Original

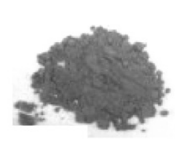

$30 \mathrm{~min}$

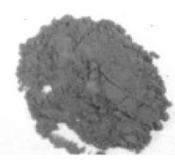

$1 \mathrm{hr}$

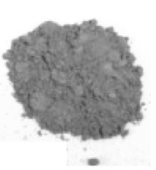

$2 \mathrm{hr}$
Fig. 1. Original and ground samples of Houttuynia cordata.
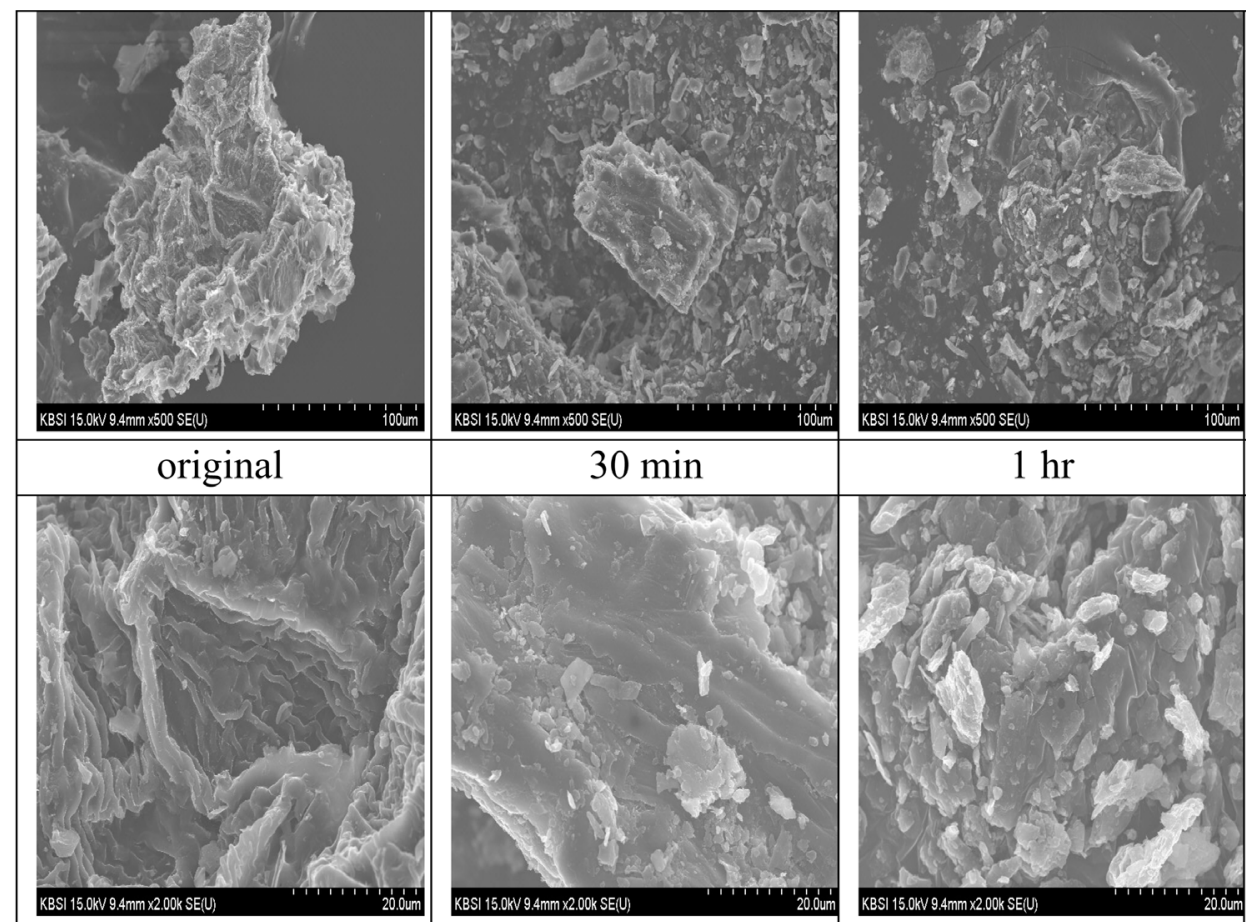

original

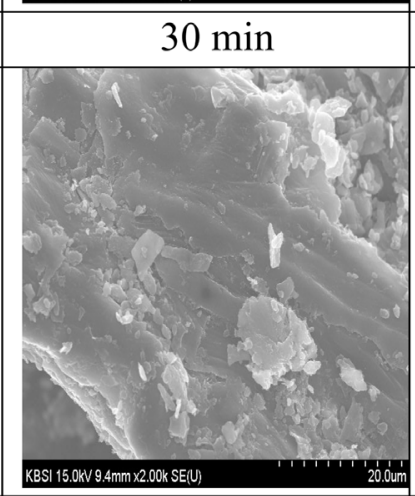

$30 \mathrm{~min}$

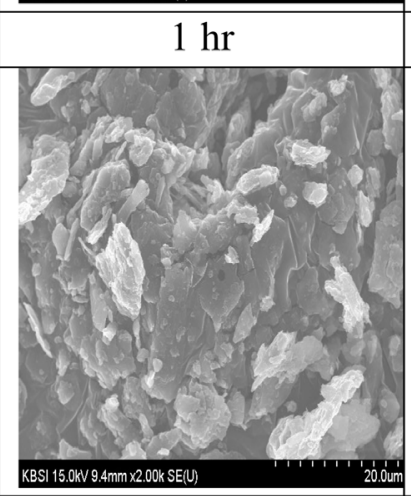

$1 \mathrm{hr}$

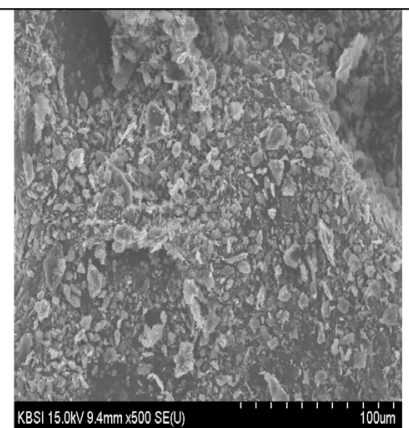

2 hrs

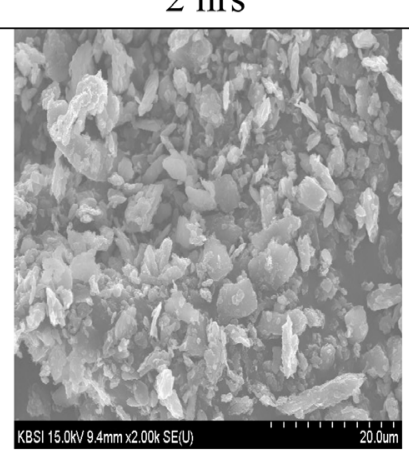

$2 \mathrm{hrs}$

Fig. 2. SEM photos of Houttuynia cordata (Upper: x500, Lower: x 2,000 times). 
Table 1. Nitrite scavenging ability from leaf extract of Houttuynia cordata.

\begin{tabular}{|c|c|c|c|c|c|}
\hline \multirow{3}{*}{\multicolumn{2}{|c|}{ Concentration $(\mu \mathrm{g} / \mathrm{mL})$}} & \multicolumn{4}{|c|}{ Nitrite scavenging ability (\%) } \\
\hline & & \multicolumn{2}{|c|}{ Methanol extract } & \multicolumn{2}{|c|}{ Ethanol extract } \\
\hline & & Control & $2 \mathrm{hr}$ & Control & $2 \mathrm{hr}$ \\
\hline \multirow[t]{4}{*}{$\mathrm{pH} 1.2$} & 50 & $57 \pm 0.21^{\mathrm{a}}$ & $69 \pm 0.84^{\mathrm{a}}$ & $58 \pm 1.47^{\mathrm{a}}$ & $64 \pm 1.47^{\mathrm{a}}$ \\
\hline & 100 & $63 \pm 1.36^{\mathrm{ab}}$ & $71 \pm 1.48^{\mathrm{ab}}$ & $61 \pm 1.69^{\mathrm{ab}}$ & $67 \pm 1.69^{\mathrm{ab}}$ \\
\hline & 300 & $68 \pm 1.42^{\mathrm{ab}}$ & $75 \pm 1.65^{\mathrm{ab}}$ & $64 \pm 1.51^{\mathrm{ab}}$ & $69 \pm 1.51^{\mathrm{ab}}$ \\
\hline & 600 & $77 \pm 1.88^{\mathrm{b}}$ & $86 \pm 1.96^{\mathrm{b}}$ & $71 \pm 1.63^{\mathrm{b}}$ & $77 \pm 1.63^{\mathrm{b}}$ \\
\hline \multirow[t]{4}{*}{$\mathrm{pH} 3.0$} & 50 & $11 \pm 1.48^{\mathrm{a}}$ & $10 \pm 1.46^{\mathrm{a}}$ & $6.0 \pm 1.11^{\mathrm{a}}$ & $7.1 \pm 1.11^{\mathrm{a}}$ \\
\hline & 100 & $25 \pm 1.42^{\mathrm{ab}}$ & $27 \pm 1.52^{\mathrm{ab}}$ & $8.8 \pm 1.49^{\mathrm{ab}}$ & $13 \pm 1.49^{\mathrm{ab}}$ \\
\hline & 300 & $30 \pm 1.39^{\mathrm{ab}}$ & $31 \pm 1.78^{\mathrm{ab}}$ & $15 \pm 1.58^{\mathrm{b}}$ & $20 \pm 1.58^{\mathrm{b}}$ \\
\hline & 600 & $32 \pm 1.70^{\mathrm{b}}$ & $39 \pm 1.72^{\mathrm{b}}$ & $18 \pm 1.77^{\mathrm{b}}$ & $28 \pm 1.77^{\mathrm{b}}$ \\
\hline \multirow[t]{4}{*}{$\mathrm{pH} 6.0$} & 50 & $0.00 \pm 0.0^{\mathrm{a}}$ & $0.00 \pm 0.0^{\mathrm{a}}$ & $0.00 \pm 0.0^{\mathrm{a}}$ & $0.00 \pm 0.0^{\mathrm{a}}$ \\
\hline & 100 & $0.00 \pm 0.0^{\mathrm{a}}$ & $0.00 \pm 0.0^{\mathrm{a}}$ & $0.00 \pm 0.0^{\mathrm{a}}$ & $0.00 \pm 0.0^{\mathrm{a}}$ \\
\hline & 300 & $0.00 \pm 0.0^{\mathrm{a}}$ & $0.00 \pm 0.0^{\mathrm{a}}$ & $0.00 \pm 0.0^{\mathrm{a}}$ & $0.00 \pm 0.0^{\mathrm{a}}$ \\
\hline & 600 & $1.7 \pm 1.18^{\mathrm{b}}$ & $3.1 \pm 1.29^{\mathrm{b}}$ & $1.06 \pm 1.39^{\mathrm{b}}$ & $2.07 \pm 1.39^{\mathrm{b}}$ \\
\hline
\end{tabular}

Table 2. Electron donating ability from leaf extract of Houttuynia cordata.

\begin{tabular}{|c|c|c|c|c|c|}
\hline \multirow{2}{*}{ Sample } & \multirow{2}{*}{$\begin{array}{l}\text { Concentration } \\
(\mu \mathrm{g} / \mathrm{mL})\end{array}$} & \multicolumn{2}{|c|}{ Electron donating ability (\%) } & \multicolumn{2}{|c|}{$\mathrm{IC}_{50}{ }^{1)}(\mu \mathrm{g} / \mathrm{mL})$} \\
\hline & & Control & $2 \mathrm{hr}$ & Control & $2 \mathrm{hr}$ \\
\hline \multirow[t]{4}{*}{ Methanol extract } & 10 & $10.01 \pm 2.72^{\mathrm{a} 2)}$ & $11.01 \pm 2.90^{\mathrm{a} 2)}$ & \multirow{4}{*}{241} & \multirow{4}{*}{223} \\
\hline & 20 & $11.47 \pm 2.79^{\mathrm{b}}$ & $13.47 \pm 2.92^{\mathrm{b}}$ & & \\
\hline & 40 & $15.39 \pm 1.87^{\mathrm{c}}$ & $28.39 \pm 1.99^{c}$ & & \\
\hline & 60 & $40.29 \pm 1.49^{\mathrm{d}}$ & $49.29 \pm 1.87^{\mathrm{d}}$ & & \\
\hline \multirow[t]{4}{*}{ Ethanol extract } & 10 & $10.10 \pm 1.86^{\mathrm{a}}$ & $9.84 \pm 1.79^{\mathrm{a}}$ & \multirow{4}{*}{278} & \multirow{4}{*}{267} \\
\hline & 20 & $11.35 \pm 1.63^{\mathrm{b}}$ & $12.35 \pm 1.87^{b}$ & & \\
\hline & 40 & $24.49 \pm 1.78^{\mathrm{c}}$ & $26.49 \pm 1.81^{\mathrm{c}}$ & & \\
\hline & 60 & $37.69 \pm 2.00^{\mathrm{d}}$ & $43.69 \pm 2.07^{\mathrm{d}}$ & & \\
\hline
\end{tabular}

${ }^{1)} \mathrm{IC}_{50}$ values represent the concentration required for $50 \%$ inhibition DPPH.

${ }^{2)}$ All values are mean \pm SD of triplicate determinations. Different letter (a-d) within the same groups differ significantly (P<0.05).

ability of methanol extraction was little higher than that of ethanol extraction.

Nitrite scavenging ability was higher for the ground sample than for the one without pretreatment showing increase from $57-77 \%$ to $69-86 \%$ for the methanol extraction while from $58-71 \%$ to $64-77 \%$ for the ethanol extraction according to extract concentration at $\mathrm{pH} 1.2$ (Table 1).

\section{Electron donating ability (EDA)}

To investigate the effect of mechanochemical pretreatment on the EDA, the sample pulverized for $2 \mathrm{hrs}$ by planetary ball mill was compared with the sample without grinding (control). The absorbance of the spectrophotometer for the solution with extract was decreased as the antioxidant of the extract got rid of the DPPH radicals in the solution. EDA for the methanol extraction was increased from $10.01-40.29 \%$ to $11.01-49.29 \%$ while those for the ethanol extraction from $10.10-37.69 \%$ to $9.84-43.69 \%$ as a result of mechanochemical pretreatment. The concentration required for $50 \%$ of DPPH inhibition was reduced from $241 \mu \mathrm{g} / \mathrm{mL}$ to $223 \mu \mathrm{g} / \mathrm{mL}$ for the methanol extraction, and from $278 \mu \mathrm{g} / \mathrm{mL}$ to $267 \mu \mathrm{g} / \mathrm{mL}$ for the ethanol extraction. 


\section{Literature Cited}

Boo, H.O., S.J. Hwang, C.S. Bae, S.H. Park and W.S. Song. 2011. Antioxidant activity according to each kind of natural plant pigments. Korean J. Plant Res. 24(1):105-112 (in Korean).

IImura K., S.I. Takaoka, M. Suzuki and M. Hirota. 2007. Development of a particle emulsifier by mechanochemical treatment and application to the liquid-liquid extraction process. Advanced Powder Technol. 18(6):787-794.

Jun, D.H., J.T. Lee, S.J. Cheon, C.E. Lee, T.H. Kim, D.H. Lee, J.G. Han and S.H. Kim. 2009. Polyphenol and anti-oxidant effects of Kalopanax septemlobus Koidz. Leaf extracts. Korean J. Plant Res. 22(4):343-348 (in Korean).

Palaniandy S. and K.A.M. Azizli. 2009. Mechanochemical effects on talc during fine grinding process in a jet mill. Int. J. Miner. Process. 92:22-33.

Xie, J., L. Shi, X. Zhu, P. Wang, Y. Zhao and W. Su. 2011. Mechanochemical-assisted efficient extraction of rutin from Hibiscus mutabilis L. Innovative Food Science and Emerging
Technologies 12:146-152.

Xie, J., H. Li, X. Zhu, P. Wang, W and Su. 2011. Efficient and selective extraction of magnolol from Magnolia officinalis by mechanochemical extraction technique. Chemical Engineering and Processing 50:325-330.

Yang, Y.J., H.J. Kim, S.H. Kang and S.C. Kang. 2011. Screening of natural herb resources for anti-oxidative effects in Korea. Korean J. Plant Res. 24(1):1-9 (in Korean).

Zhu, X.Y., Y.L. Mang, J. Xie, P. Wang and W. Su. 2011. Response surface optimization of mechanochemical-assisted extraction of flavonoids and terpene trilactones from Ginkgo leaves. Industrial Crops and Products 34:1041-1052.

Zubrik, A., L. Turcaniova, V.Jezova, S. Cuvanova and M. Skybova. 2007. Effect of the mechanochemical activation for the extraction of diterpenes from the brown coal. J. Alloys and Compounds 434-435:837-841.

(Received 15 May 2011 ; Accepted 16 June 2011) 